\title{
Protecting the placenta
}

\section{How your environment may negatively impact the lifeline of your baby.}

\author{
BY MARIYAN J. JEYARAJAH \\ STEPHEN J. RENAUD \\ DANIEL B. HARDY \\ GENEVIEVE EASTABROOK \\ PEEYUSH K. LALA
}

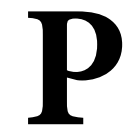

regnancy can alter practically everything about an expectant mother's life - from what they wear, to what they eat, to even physiological changes in the shape and size of their brain. All these exciting changes are simply the pregnant mother's response to welcome their new child.

In addition to their baby, another incredible aspect to pregnancy is the growth of a completely new organ: the placenta. The placenta acts as the baby's lifeline and provides the baby with all necessary nutrients and oxygen. The placenta is responsive to its surrounding environment and can serve as a living barrier, adapting and responding to negative environmental factors that can jeopardize the health of the baby [1]. However, there are limits to the placenta's ability to adapt, and therefore, understanding the everyday environmental risks that can harm both placenta and baby can help ensure the proper development of the child.

One of the leading environmental factors resulting in poor pregnancy outcomes is drug use. Currently in Canada, one in five women report marijuana use as a common activity during pregnancy [2]. With the recent legalization of marijuana in Canada, this is a troubling statistic, as not much is known about the effects of cannabis on pregnancy. Daniel Hardy, an associate professor of physiology and pharmacology at Western University advises against marijuana intake during pregnancy. A recent study from his lab found that exposure to $\triangle 9$-THC, the psychoactive component of cannabis, can result in poor placental outcomes [2]. Pregnant rats given $\triangle 9-\mathrm{THC}$

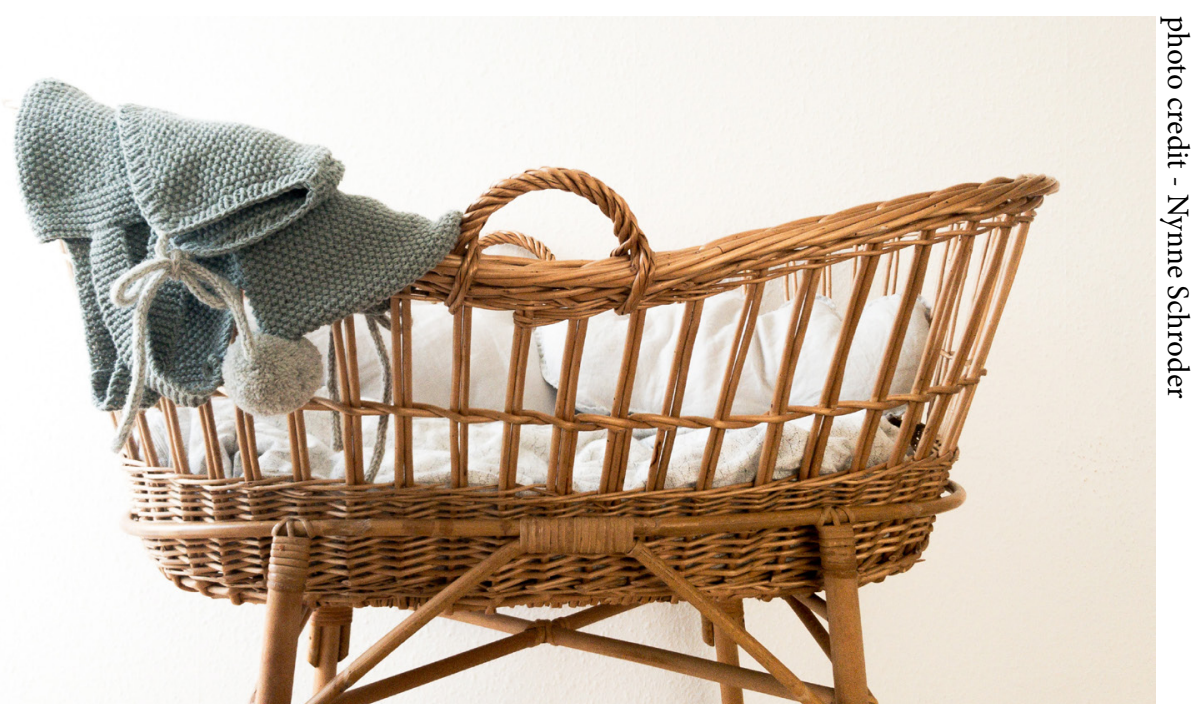

Pregnancy outcomes can be influenced by numerous factors including drug use, viral infection, and socioeconomic status.

showed greatly reduced placental function and transfer of nutrients and oxygen to the baby. Moreover, $\triangle 9$-THC resulted in the rats giving birth to lowweight, or growth-restricted babies, an outcome often associated with an increased risk of cardiovascular and metabolic disorders in humans $[2,3]$. Another key environmental factor that can negatively impact the health of a baby is poor nutrition. In Canada, approximately 2.5 million women are classified as low socioeconomic status [4]. These individuals often face greater challenges in obtaining nutritious foods and frequently find themselves consuming high carb, high fat diets. This can have damaging effects on the placenta and can cause the placenta to mature too quickly [5]. When placentas mature rapidly, they age prematurely, and produce an unusually low oxygen atmosphere. This environment can result in fetal growth restriction.

There are other environmental factors that can harm the placenta and baby that lie outside the control of the mother, for example, viral infection. Zika virus is most prevalent in coun- tries with warm climates. However, due to warming temperatures associated with climate change, the range of this virus has vastly expanded. Mosquitos carrying Zika have traveled from Africa and have infected pregnant mothers living all over the world, including the Americas and Europe. In the instance of Zika infection, after being bit by a mosquito carrying Zika, the virus has been shown to cross the placental barrier, alter oxygen transport activity, and result in children with microcephaly, a condition in which the brain is not correctly developed [6]. Influenza, or the yearly flu is another virus that may be damaging to pregnancy. Pregnant mothers who contract influenza in their third trimester are more susceptible to respiratory defects and have an increased risk of fatality [7]. Viral infections such as influenza may for the most part seem out of our control, but obstetrician and gynecologist, Dr. Genevieve Eastabrook suggests that expectant mothers and the public can take matters into their own hands by receiving yearly vaccinations.

Lastly, one of the major environmental concerns faced by pregnant mothers is misinformation from social 


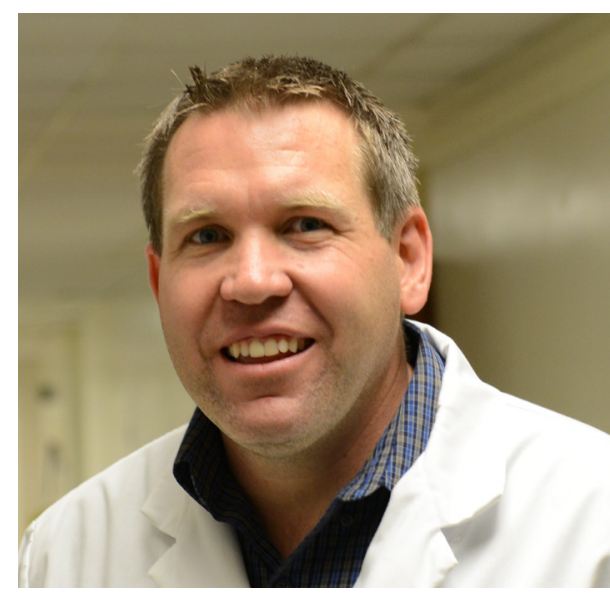

Daniel Hardy

media and popular culture. In today's society, some celebrities feel entitled to provide information to their followers, and this advice is often taken at face value without scientific rigor. This creates disparity in the quality of information and consequently, women can be exposed to a lot of misinformation. This ranges from fads promoting lotus births - where the umbilical cord is left to naturally detach from the fetus to even consuming the placenta. There is no scientific evidence indicating any benefit to these practices $[8,9]$. Lotus births and consumption of the placenta will more likely lead to negative side effects such as an increased risk of infection $[8,9]$. To combat misinformation, Dr. Jen Gunter, a Canadian obstetrician and gynaecologist advocates for women's health through social media. Gunter recently published the book, "the Vagina Bible", where she utilizes pop culture tactics to dispel incorrect information [10]. She provides information to expectant mothers, creating opportunities for them to implement good practices and give their babies a chance for a healthy start.

It is evident that many factors can influence the outcome of pregnancy. Specifically, an expectant parent's surrounding environment can create significant challenges to the placenta and place both mother and baby in harm's way. However, clinician and scientist, Dr. Peeyush Lala from Western University says there's not too much reason for concern. The placenta is a resilient organ that can take care of all the baby's needs. In today's world, most individuals undergo pregnancy with little to no complications. Lala's

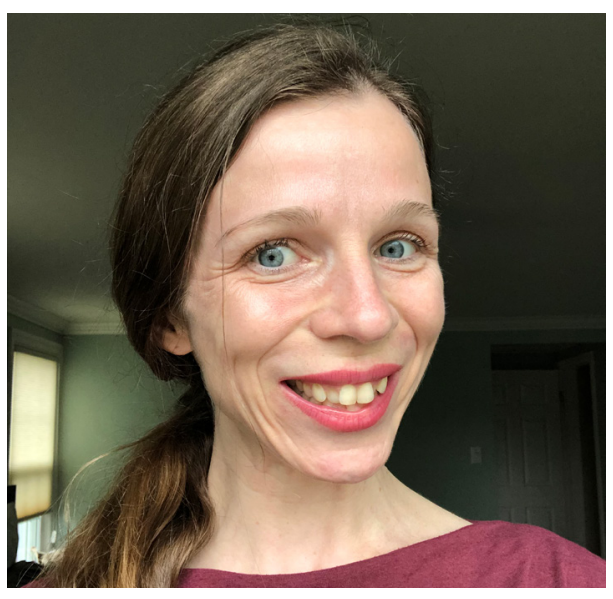

Genevieve Eastabrook

advice to any pregnant mother is to follow the instructions of their doctor, eat balanced meals, not partake in risky behaviours such as drugs and alcohol, and to simply "cherish the moment." To provide even more support for pregnant mothers, researchers such as Stephen Renaud, an assistant professor of anatomy and cell biology at Western University, aims to understand how the placenta develops to safeguard growth of the baby. Renaud's lab focuses on understanding the genetic and immune regulation of the placenta, trying to comprehend how it develops and functions during pregnancy. He believes that by unraveling the mysteries of the organ, we can best support and nurture it, so that it may do its job to serve as the baby's lifeline.

\section{REFERENCES}

1. Maltepe E, Fisher SJ. Placenta: the forgotten organ. Annu Rev Cell Dev Biol. 2015 Apr 24;31:523-52.

2. Natale B V, Gustin KN, Lee K, Holloway AC, Laviolette SR, Natale DRC, et al. $\Delta$ 9-tetrahydrocannabinol exposure during rat pregnancy leads to symmetrical fetal growth restriction and labyrinth-specific vascular defects in the placenta. Sci Rep. 2020 Apr 24;10(1):544.

3. Gillies R, Lee K, Vanin S, Laviolette SR, Holloway AC, Arany E, et al. Maternal exposure to $\Delta 9$-tetrahydrocannabinol impairs female offspring glucose homeostasis and endocrine pancreatic development in the rat. Reprod Toxicol. 2020 Apr 26; Available from: http://dx.doi. org/10.1016/j.reprotox.2020.04.070

4. Canadian Women's Foundation [Internet]. The Facts about Women and Poverty in Canada [cited 2020 April 28]. Available from: https://canadianwomen.org/thefacts/womens-poverty/

5. Huynh J, Dawson D, Roberts D, Bentley-Lewis R. A systematic review of placental pathology in maternal diabetes mellitus. Placenta. 2015 Apr 24;36(2):101-

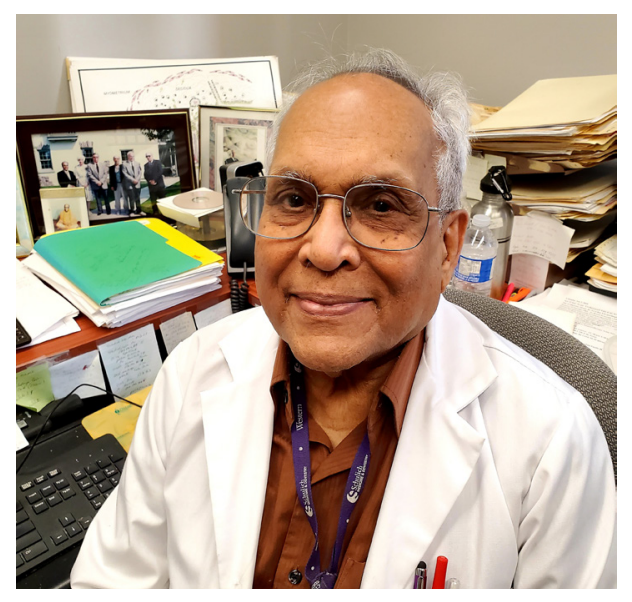

Peeyush Lala

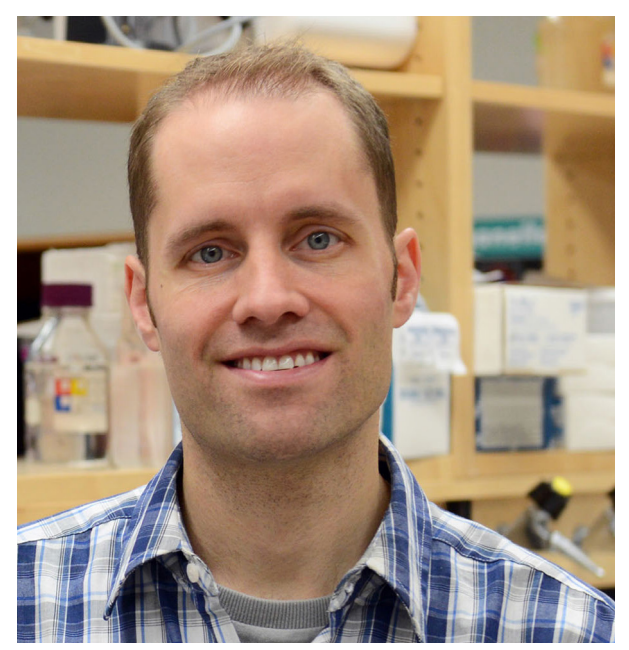

Stephen Renaud

14.

6. Khaiboullina SF, Ribeiro FM, Uppal T, Martynova E V, Rizvanov AA, Verma SC. Zika virus transmission through blood tissue barriers. Front Microbiol. 2019 Apr 26;10:1465.

7. Silasi M, Cardenas I, Kwon J-Y, Racicot K, Aldo P, Mor G. Viral infections during pregnancy. Am J Reprod Immunol. 2015 Apr 24;73(3):199-213.

8. Science-Based Medicine [Internet]. Lotus Birth: No Benefit, Plenty of Risk [cited 2020 Apr 28]. Available from: https:// sciencebasedmedicine.org/lotus-birth-nobenefit-plenty-of-risk/

9. Morris E, Slomp C, Hippman C, Inglis A, Carrion P, Batallones R, et al. A Matched Cohort Study of Postpartum Placentophagy in Women With a History of Mood Disorders: No Evidence for Impact on Mood, Energy, Vitamin B12 Levels, or Lactation. J Obstet Gynaecol Canada. 2019 Sep 1;41(9):1330-7.

10. 10. CTV News. [Internet] "Vagina Bible" aims to dispel myths and misinformation about genital health. CTV News [cited 2020 April 28]. Available from: https://www.ctvnews.ca/health/vagina-bible-aims-to-dispel-myths-and-misinformation-about-geni-

tal-health-1.4575352?cache=yesclipId104062\%3FclipId\%3D89925\%3FautoPlay\%3Dtrue 


\section{Northern Canadian Indigenous and the environment}

\section{A relationship compromised by colonization and cli- mate change.}

\author{
BY COLIN JAMIESON
}

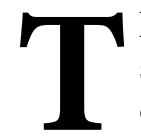
he environment is a complex system comprised of social, cultural, and natural forces that can regularly influence one's health and wellbeing. It has power over both opportunity and behavior and has historically led to human adaptation. This is particularly true among Indigenous populations of Canada. Canadian Indigenous peoples share a strong, longstanding relationship with the natural environment and have been driven to adapt as a result of colonialism, systemic oppression and exclusion, forced displacement, and climate change [1-3]. Harmony between humans and the natural world is highly revered among Indigenous communities. Indigenous peoples often rely on the natural environment for sustenance and in return they cherish and respect it [4-5]. This harmonious relationship is often seen as a fundamental component of Indigenous culture; in fact, many Indigenous peoples integrate environmental health into their sense of wellness or personal well-being [6]. Andrew Papadopoulos, an associate professor in population medicine at the University of Guelph, explained that Indigenous peoples often "look at the absence of caribou, the rising of temperatures, the melting of ice, the presence of trichinella in walruses, and the absence of other traditional food sources" when expressing their wellbeing.

As a result of colonization, Indigenous populations have been distanced from their traditional lands - thereby compromising traditional food practices and the pertinence of local knowledge [5]. Despite contributing little to climate change, these communities have been displaced to regions experiencing the most rapid environmental changes. Rising environmental temperatures at the Canadian Arctic has led to unstable ice conditions and has altered animal migration patterns [7-9]. Traditional Inuit peoples rely on the conditions of the sea ice to enable safe travel to hunting and fishing grounds, and thus, unstable ice conditions have hindered access to traditional food sources. This has led to a growing prevalence of food insecurity colonization. among Inuit households increasing the risk of hunger and malnutrition among these individuals. In fact, a study from McGill University found that food insecurity was three times more prevalent among Inuit compared to off-reserve Indigenous households [1]. A Canadian study also found that increasing sea ice instability has restricted Inuit peoples' freedom of movement, increased physical dangers associated with hunting and fishing, and has significantly disturbed traditional ways of living [5]. Ice trips are associated with social bonding and the transference of traditional knowledge, as climate change has made these trips more dangerous and less practical it has disconnected Inuit peoples from their environment - causing a significant loss of place [5]. Cultural disruption compounded with social isolation and endangered personal safety has resulted in increased levels of stress and worsened mental health among these populations.

When providing Indigenous communities with support, it is vital to build relationships and work in consultation. Papadopoulos stressed the importance of providing "care, treatment, or services in a culturally appropriate manner." In the context of Indigenous communities, it is important to recognize their desire for self-governance and autonomy as well as the importance of tradition within their culture [10-11]. When pathogenic growth occurred in

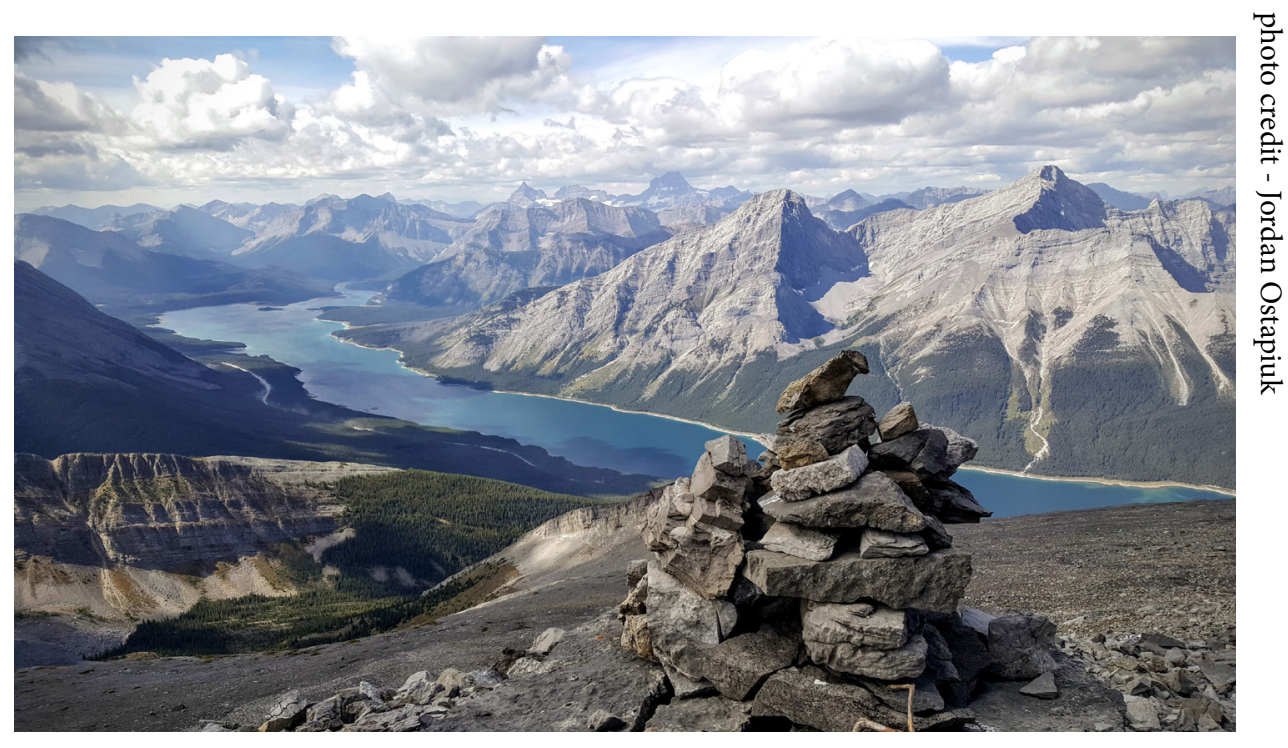

The Bow River in Alberta, Canada - called Makhabn in the Blackfoot language - was used by Indigenous people for travel, hunting, and fishing, long before European 